\title{
CORRIGENDUM
}

\section{Effect of Herceptin on the development and progression of skeletal metastases in a xenograft model of human breast cancer}

\author{
P Khalili, A Arakelian, G Chen, G Singh and SA Rabbani
}

Oncogene (2006) 25, 492. doi:10.1038/sj.onc.1209316

Correction to: Oncogene 2005; 24: 6657-6666.

doi:10.1038/sj.onc. 1208790

Published online 8 August 2005
Since publication of the above manuscript, the authors have identified an error in Figure 9. The revised version of the figure is given below. a
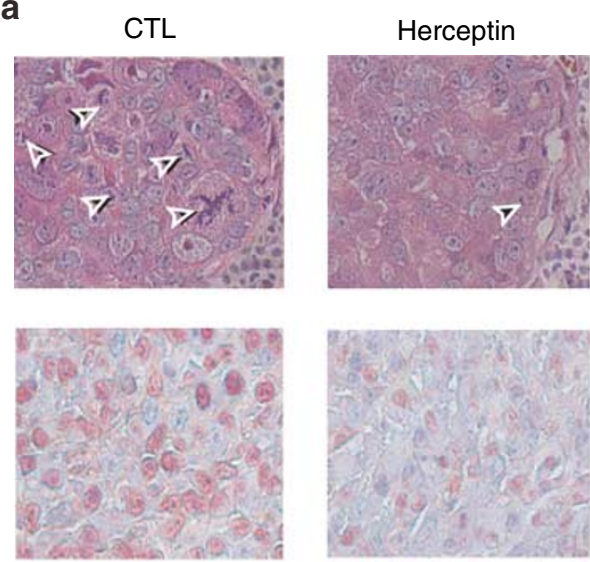

b
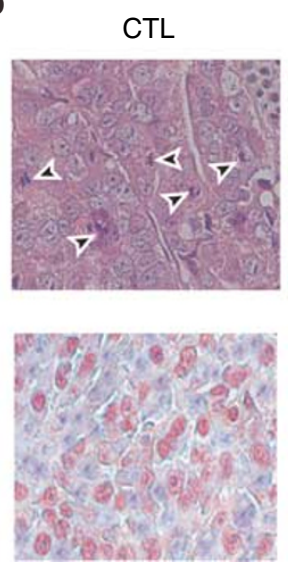

Herceptin
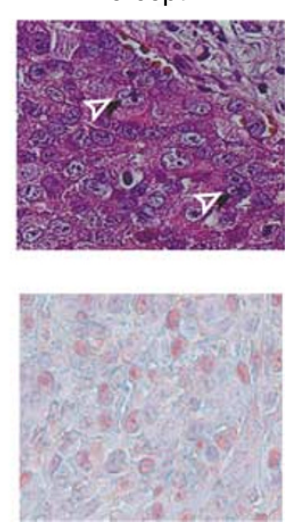
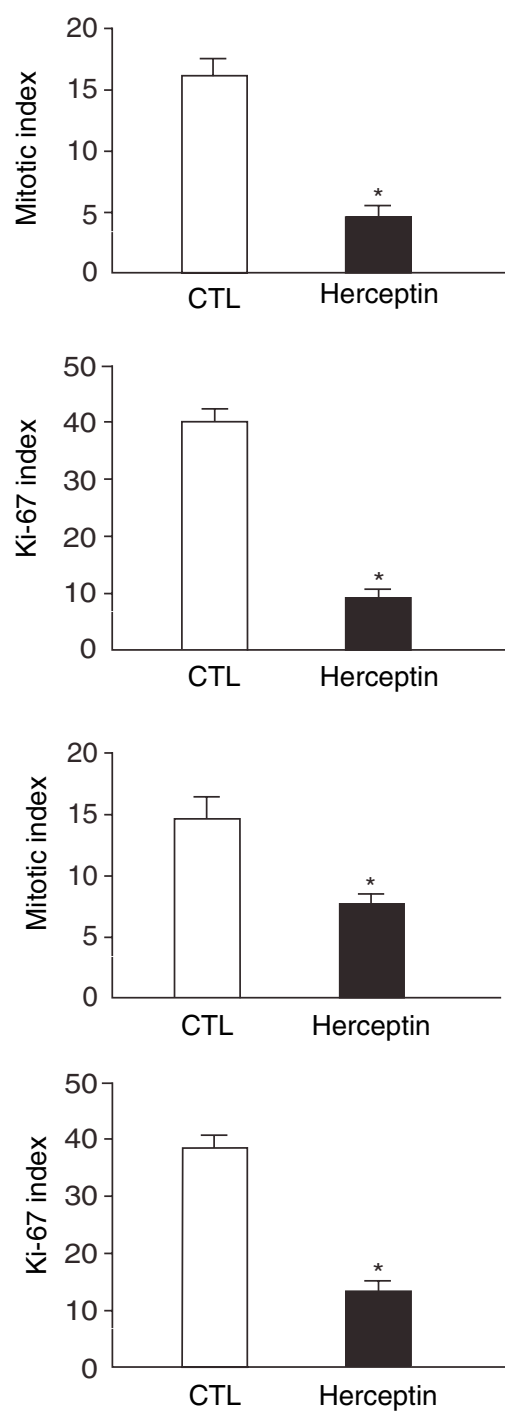